\section{University wins injunction against animal activists}

Five animal-rights activists and associates were permanently barred last week by a California court from harassing researchers at the University of California, Los Angeles (UCLA).

The permanent injunction, awarded on 27 May, follows a temporary restraining order made in February last year (see Nature $451,1041 ; 2008)$, which was converted into a preliminary injunction that April. It comes after repeated threats, including home invasions and fire bombings, aimed at UCLA researchers who use animals in experiments.

The activists were identified as associated with the Animal Liberation Front, the UCLA Primate Freedom Project or the Animal Liberation Brigade. Two of them face multiple felony counts for an alleged conspiracy of stalking and threatening UCLA researchers; their pre-trial hearing will be held on 14 July. Both pleaded not guilty.

\section{Economic gloom threatens renewables investment}

Renewable-energy projects are struggling the most in terms of investment in the energy sector, according to a report published by the International Energy Agency (IEA) on 27 May.

The agency predicts that a sharp fall in energy demand could see global electricity consumption drop by up to $3.5 \%$ this year the first contraction since 1945. Combined with tighter access to credit, the weak demand means that many firms in the oil, gas and coal sectors are having to cut back on their spending. The slump is even more pronounced for renewables projects, which are often developed by smaller companies.

Government stimulus spending will

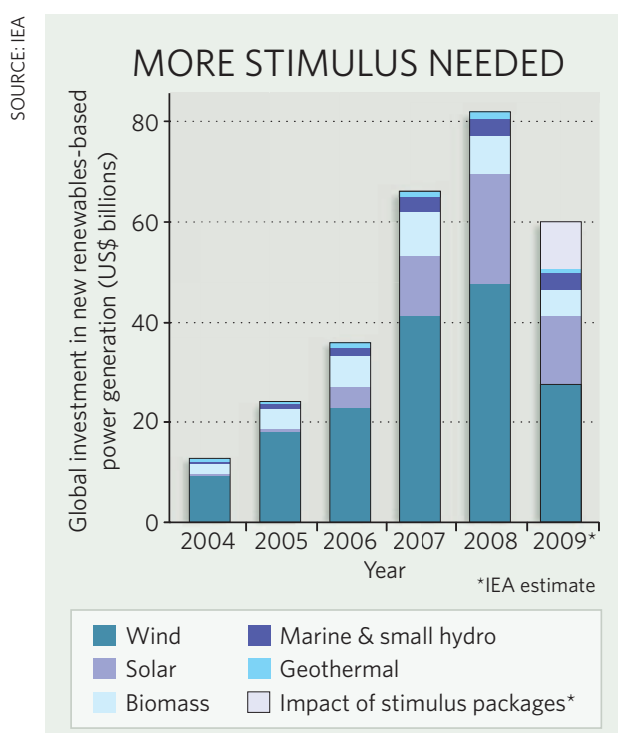

trigger additional public and private investment in renewable energy (see chart), but the agency thinks that the stimulus funding needs to be increased sixfold if patterns of energy use are to be altered sufficiently to keep the global temperature rise within $2^{\circ} \mathrm{C}$ of pre-industrial levels. See also page 740 .

\section{Malaria vaccine enters phase III clinical trials}

GlaxoSmithKline's RTS,S malaria vaccine entered its final phase of pre-approval testing last week in Bagamoyo, Tanzania, raising hopes that the drug could be licensed for widespread use by 2012 .

On 26 May, five infants aged 5-17 months were inoculated with the vaccine. In the coming months, the study will become the largest ever trial of a malaria vaccine candidate, involving 16,000 children under the age of two at eleven sites in seven African countries.

RTS,S is so far the only malaria vaccine to make it to phase III trials, in a development process that has taken more than two decades and cost over US\$400 million (see Nature 451, 1042-1046; 2008). For a longer version of this story, see http://tinyurl.com/malvac.

\section{Africa declares its stance for climate-change talks}

More than 300 African negotiators, ministers, experts and agency representatives converged on Nairobi last week to forge a shared vision on climate change. Their conclusion: to ask for more financial and technical support to help Africa cope, but with few specifics.

"It was difficult to agree on how much to ask for," says Sputnik Ratner, a spokesman for Buyelwa Sonjica, South Africa's minister of water and environmental affairs, who chaired the ministerial meetings. "Different countries have different needs."

The 'Nairobi declaration' also asks industrialized countries to reduce their greenhouse-gas emissions towards the upper end of the pledged $25-40 \%$ cut below 1990 levels by 2020. The declaration is meant to serve as a starting point for Africa's negotiations at climate meetings being held this week in Bonn, Germany, and scheduled for December in Copenhagen, to hammer out a successor to the Kyoto Protocol.

Despite the declaration's vagueness, the United Nations Environment Programme hailed it as a "landmark position" and a "major milestone on the road for combating climate change on the continent".

For a longer version of this story, see http://tinyurl.com/afclim.

\title{
Changes at the top for Indian science
}

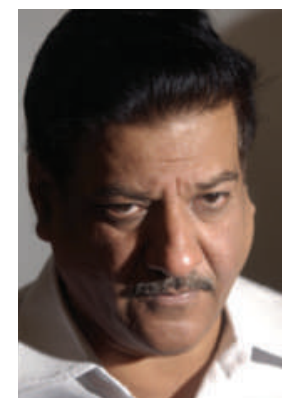

Prithviraj Chavan.
India's Prime

Minister Manmohan Singh last week named Prithviraj Chavan as his new science minister, after spring elections returned Singh's party to power (see Nature 459, 311; 2009).

Chavan, who has a master's degree in engineering from the University of California, Berkeley, takes charge of the ministries of science and technology and of Earth sciences. But he will continue as minister of state in the prime minister's office, a role he has held since 2004 , and which involves interactions with the space and atomic-energy agencies.

"I am personally happy that we have a science minister who is also ideally positioned in the prime minister's office," says Thirumalachari Ramasami, secretary for the department of science and technology. With former science minister Kapil Sibal placed in charge of the human-resource development (education) ministry, Ramasami says the combination "signifies a very bright future for Indian science as a whole".

\section{Open-access publishing gains another convert}

University College London (UCL) became the latest institution to adopt an open-access publishing policy this week, adding to the rapid increase in such mandates over the past year.

The policy, announced on 3 June, will see all of the university's research placed online in an institutional free-to-access repository - but only where publishers' copyright rules allow. The system will take effect from the beginning of the 2009-10 academic year.

"Open-access mandates [from institutions and funding bodies] have almost doubled globally in the year that has elapsed since Harvard's mandate in May 2008," says Stevan Harnad, an advocate of open access at the University of Southampton, UK.

\footnotetext{
Correction

In the News story 'Fusion dreams delayed'

(Nature 459, 488-489; 2009), the pie chart of ITER partners inadvertently omitted India. Like all non-European Union partners, India contributes $9 \%$ to the overall cost of the project. The html version of the story has been amended to show the correct chart, and a corrected PDF can be downloaded from http://tinyurl.com/nnwt9w.
} 